\title{
Research Article \\ Building Structure Simulation System Based on BIM and Computer Model
}

\author{
Bao Zhu and Huan Feng \\ School of Civil Engineering, Chuzhou Vocational and Technical College, Chuzhou 239000, China \\ Correspondence should be addressed to Huan Feng; fenghuan@chzc.edu.cn
}

Received 14 July 2021; Revised 14 August 2021; Accepted 20 October 2021; Published 8 November 2021

Academic Editor: Mu Zhou

Copyright (c) 2021 Bao Zhu and Huan Feng. This is an open access article distributed under the Creative Commons Attribution License, which permits unrestricted use, distribution, and reproduction in any medium, provided the original work is properly cited.

\begin{abstract}
This paper does some research and discussion on the finite element analysis of a building structure, especially the computer graphics simulation method in building structure simulation. Moreover, with the support of BIM technology and computer finite element simulation technology, this paper constructs a building structure simulation system and analyzes the building structure simulation system based on actual conditions such as building structure and stress load. In addition, this paper improves the traditional structural analysis algorithm and designs experiments to evaluate the effect of the method proposed in this paper and analyze the data in the form of simulation to compare the validity of the test results. Finally, an experiment is designed to evaluate the data processing capability of the test system in this paper. The experimental analysis results verify the effectiveness of the method in this paper, which can provide relevant theoretical references for subsequent building structure simulation.
\end{abstract}

\section{Introduction}

With the development of urbanization in my country, the cost management objectives of construction projects have shifted to a deeper level. Construction engineering refers to the engineering entity formed through the construction of various types of houses and their ancillary facilities and the installation of supporting lines, pipelines, and equipment. In this process, if relevant optimization theories can be used to systematically study the project, the goal of optimizing resource allocation and reducing construction costs can be achieved. China has gone through decades of experience in modern construction engineering and the process of exploring the optimal allocation of construction resources. It has formed a complete set of systems for construction projects, from cost decision-making and design budgets to construction engineering supervision and management. However, due to the inadequate use of the rapid development of modern information technology, the cost control and management methods of Chinese construction companies are relatively backward, and many projects still remain in manual manipulation [1]. As the country's requirements for construction companies increase and the factors that affect the cost control of construction companies continue to increase, the simple manual control method in the past can no longer meet the business growth needs of construction companies. To improve the current cost control system of construction enterprises, a large-scale information system must be established to conduct detailed analysis of various data to determine the most optimized construction plan. In the process of market economy development, construction companies are facing fiercer market competition. The key to whether an enterprise can be invincible in the market competition is whether it can provide the society with high-quality, short-term, and lowcost construction products. Therefore, cost management has become the core content of project construction management [2]. The cost of construction projects refers to a form of currency measurement by which construction companies use the project as the object of cost accounting to measure the transfer value of the production materials consumed in the construction process and the value created by the necessary labor of the laborers. The cost of construction projects is also called engineering cost, which is the main product cost of construction enterprises. On the premise of ensuring the quality of construction, one of the ways to reduce the cost of construction 
projects is to establish a project cost management information system, which is also the most feasible and efficient management method currently. The implementation of computerassisted informatization can not only shorten the processing time of relevant data but also facilitate the management of various comprehensive cost data. At the same time, it enables project managers to grasp complete and correct information in a timely manner through organized information circulation, thereby providing strong information support for project cost management. It can be seen that to truly realize the "dynamic, full-process, and all-round" of the project cost management system, it is necessary to realize the integrated development of cost information and establish a dynamic management system [3].

In order to meet people's increasingly abundant activity needs, a large number of buildings with unique appearances, rich functions, and reasonable structures have emerged. At the same time, in order to better realize the architect's design concept and show a more perfect design form, many buildings need to seek a breakthrough from the traditional reinforced concrete model. With the application of new materials such as high strength and light weight, many new space systems have been realized, such as space string beam structure, opening and closing space structure, cable dome structure, and other systems. In order to improve the structural efficiency of the space structure, prestressing technology is introduced, and a new type of prestressed steel structure system is formed by reasonably changing the stress state of different structures, so as to realize the designer's expected plan effect. The prestressed steel structure has attracted the attention of engineers and researchers because of its good mechanical properties and broad application prospects. Meanwhile, it has become a hot spot and cutting-edge science that conforms to the development requirements of the times, and it is also one of the main trends in the development of space structures in recent years. Compared with traditional concrete structures, a prestressed steel structure has many advantages in structural systems and materials, such as lighter weight, short construction period, and simple structure. Therefore, it is widely used in large-span spatial structures.

Based on BIM and computer models, this article simulates building structures.

\section{Related Work}

By analyzing the relevant construction codes and standards of American concrete structure engineering, literature [4] pointed out that there is no clear foundation for the load value of the formwork design at present and then proposed the necessity of load investigation during the construction period. Literature [5] conducted on-site surveys of the live load on the floor before and after the concrete pouring of the cast-in-place reinforced concrete structure under construction. Moreover, it used the floor live load survey method during the construction period to obtain the field measured data and used the analysis method to obtain the statistical parameters of the live load during the construction period. Literature [6] proposed a test method for construction live load, which can truly record the change process of construc- tion live load, and can be used to study the law of more complicated construction live load such as impact load. Literature [7] analyzed and studied the dynamic load model of the floor formwork during concrete pouring and constructed a probability model according to the relevant factors that affect the dynamic load of the floor formwork. Literature [8] conducted field survey and research on live load of cast-in-situ reinforced concrete structure and discussed and summarized the law and distribution characteristics of floor live load during the construction of cast-in-situ reinforced concrete structure. Literature [9] studied the impact of the impact load caused by pouring concrete during the construction process on the temporary load-bearing system composed of the partially resistive concrete structure and the formwork and its support and proposed a method for calculating the dynamic influence of the impact load generated during concrete pouring on the "time-varying structure." Literature [10] studied the impact of the dynamic load on the temporary load-bearing system caused by a small mobile dump truck that transports concrete when driving on a newly poured concrete floor. After conducting a large-scale field survey and statistical analysis, literature [11] summarized the law of construction live load and carried out quantitative analysis on it.

Literature [12] conducted field tests on flat-slab apartments, analyzed the applicability of the simplified hand calculation method of computer simulation, and believed that the simplified method underestimated the maximum load of the floor. Literature [13] analyzed the influence of floor stiffness and unequal deflection of floor slab on load transfer and compared the theoretical and measured values of supporting load and floor load. Literature [14] carried out on-site measurements for a shear wall structure to try to analyze the load transfer data during construction. However, it obtained some data by measuring the support of the floor slab and the embedded steel bars in the floor slab, but some of the data is not logical. The subsequent testing work focused on the force analysis of the template and support. Through a series of investigations and field tests, literature [15] pointed out the possibility of obtaining data on-site and pointed out that the load on the support, the data during the curing period of the concrete slab, and the information of the multilayer support can all be obtained through the test. Literature [16] conducted field tests on low-rise concrete structures under construction. Through the measurement of the support load of the formwork during construction, it analyzed the applicability of the design load recommended by ACI, compared the order of magnitude of the lateral support and the vertical support load, and pointed out that the removal of the formwork support will cause a large change in the distribution of the floor and support load. Literature [17] measured the influence of different loading paths, different load sizes, and other factors on the load effect of scaffolding. Literature [18] conducted continuous observation experiments on cast-in-place frame structures and obtained important data. The test found that with the passage of time, the load was redistributed among the various floors, which was prominently manifested in the fact that the newly poured concrete floor slabs began to not bear the load to gradually bear part of the load. Literature [19] provided a useful discussion on the analysis of reinforced concrete structures 
during the construction period considering load redistribution. However, the calculation of the load redistribution amount in the model as a fixed proportion of the weight of the floor does not conform to the time-varying structural characteristics, so it may sometimes cause a large error that is dangerous.

\section{Selection of Model Element Type}

The element library of the LS-DYNA program includes solid elements, shell elements, beam elements, rod elements, inertia and mass elements, and spring damping elements. The common feature of these elements is that they all use low-order elements with linear displacement interpolation functions, and the default algorithm is a reduced integration algorithm. The experience of calculation and analysis shows that these explicit dynamic elements of linear displacement interpolation function and single-point integration algorithm can be well used for the analysis of various large deformation and material nonlinear problems.

For the upper building structure, the 3D solid unit SOLID164 is used, as shown in Figure 1. Its basic characteristics are as follows [20]:

(1) There are 8 nodes. For each node, its displacement degree of freedom has practical significance

(2) It adopts a single-point integration algorithm by default

(3) It can adopt Lagrange form or ALE form

(4) It can be degenerated into degenerate units such as prisms and pyramids

(5) When applying pressure to the surface of the unit, it is necessary to pay special attention to the numbering of the surface

(6) It supports most of LS-DYNA material algorithms

(7) The volume cannot be zero

(8) SOLID164 element must be defined by 8 nodes

The thin shell element is selected to simulate the earth plane, namely, SHELL163, as shown in Figure 2. Its basic characteristics are as follows:

(1) This element is a 4-node spatial thin shell element. For each node, the displacement and rotation of the node need to be considered

(2) The default algorithm adopts the shell element algorithm of Belytschko-Tsay single point integration

(3) For various shell element algorithms, the number of integration points along the thickness direction can be selected

(4) The thickness of the shell is defined by real parameters and cannot be zero

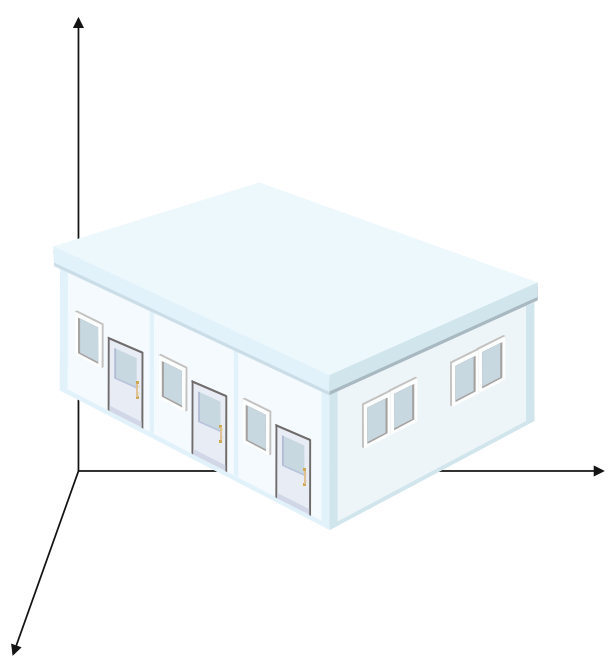

FIGURE 1: SOLID164 unit.

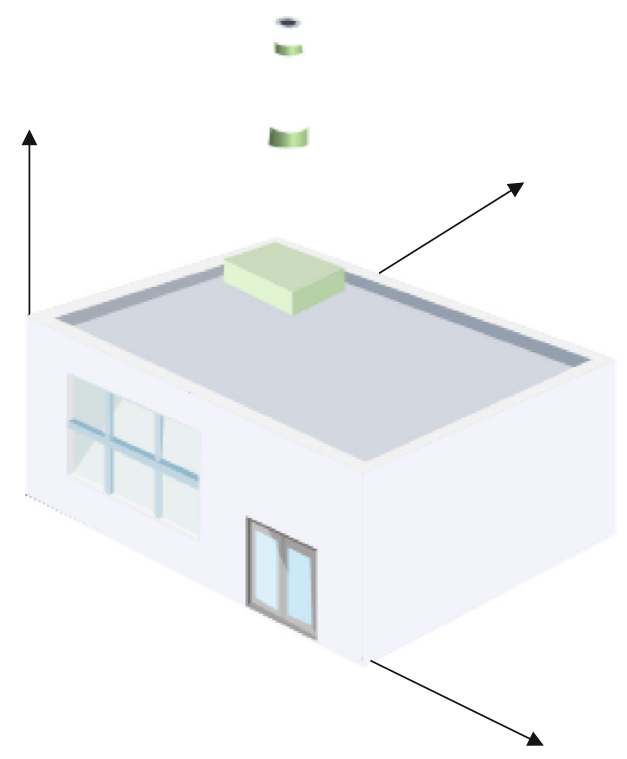

FIGURE 2: SHELL163 unit.

(5) The area of the SHELL163 element cannot be zero, and the degenerate element can be defined by the same node appearing twice

(6) SHELL163 element supports most material model algorithms

3.1. Basic Explicit Algorithm for 3D SOLID Elements. This paper takes three-dimensional 8-node solid elements as an example to introduce the explicit integration algorithm of LS-DYNA.

The main algorithm of LS-DYNA adopts the Lagrangian incremental method that tracks the trajectory of the particle. For the particle at the initial moment of space point $\left(\alpha_{1}\right.$, $\left.\alpha_{2}, \alpha_{3}\right)$, the trajectory equation is [21]

$$
x_{i}=x_{i}(\alpha, t)
$$




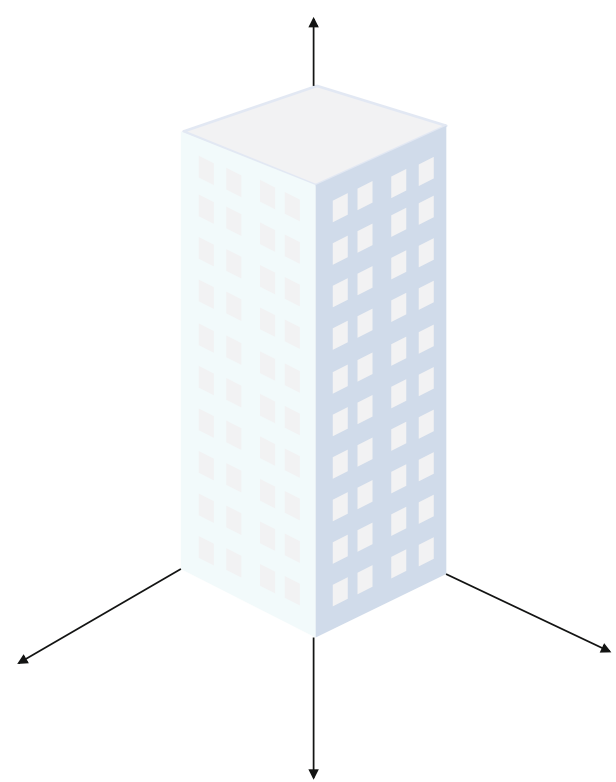

FIGURE 3: Schematic diagram of 8-node entity isoparametric unit.

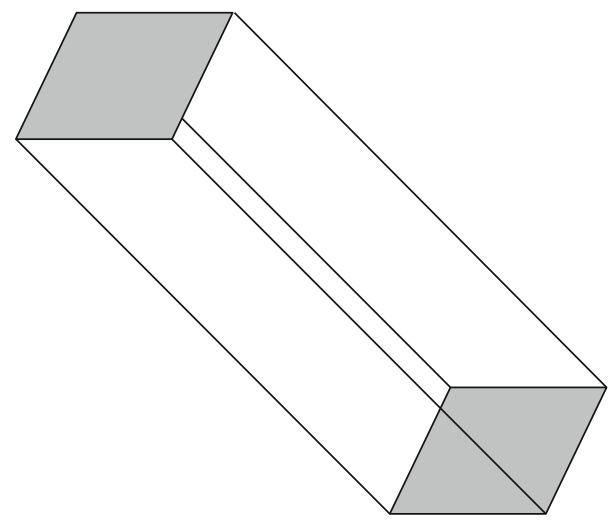

FIGURE 4: Spatial model of columns with central reinforcement.

Among them, $\alpha$ represents the initial position $\left(\alpha_{1}, \alpha_{2}, \alpha_{3}\right)$ of the material point, and the initial conditions of movement are

$$
\begin{gathered}
x_{i}(\alpha, 0)=\alpha_{i}, \\
\dot{x}_{i}(\alpha, 0)=v_{i}(\alpha) .
\end{gathered}
$$

In addition, the differential equation of motion for the elastodynamic space problem is

$$
\sum_{j=1}^{3} \frac{\partial \sigma_{i j}}{\partial x_{j}}+f_{i}=\rho \ddot{u}_{i}
$$

It satisfies the following boundary conditions:

(1) The displacement boundary condition is

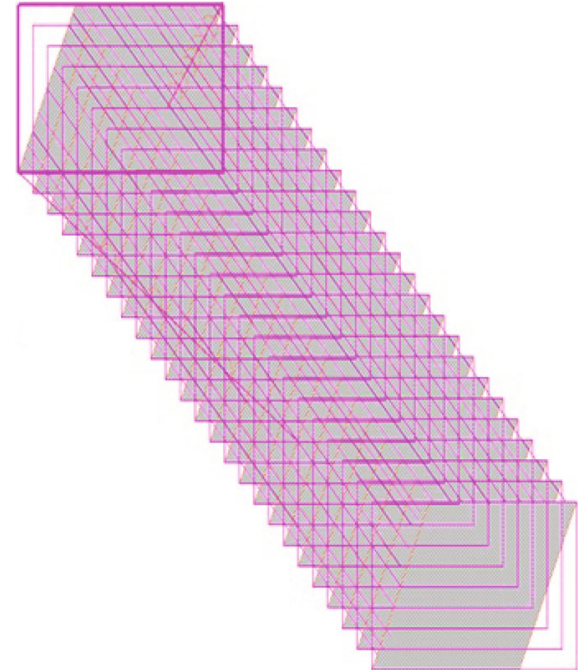

FIGURE 5: Rebar mesh model of columns with central reinforcement.

$$
u_{i}=\bar{u}_{i}
$$

on the displacement boundary $\partial b_{1}$

(2) The stress boundary condition is

$$
\sum_{j=1}^{3} \sigma_{i j} n_{j}=\bar{T}_{i}
$$

on the stress boundary $\partial b_{2}$

(3) The jumping conditions at the discontinuity of the sliding contact surface displacement are

$$
\sum_{j=1}^{3}\left(\sigma_{i j}^{+}-\sigma_{i j}^{-}\right) n_{j}=0
$$

(4) When $x_{i}^{+}=x_{i}^{-}$, contact occurs along the inner contact boundary

The integral form of the differential equation of motion is (the principle of minimum potential energy)

$$
\delta \prod=\int_{v} \sum_{i=1}^{3}\left(\rho \ddot{x}_{i}-f_{i}\right) \delta u_{i} d V+\int_{v} \sum_{i=1}^{3} \sum_{j=3}^{3} \sigma_{i j} \delta \varepsilon_{i j} d V-\int_{\partial b_{2}} \sum_{i=1}^{3} \bar{T}_{i} \delta u_{i} d s=0 .
$$

Among them, $\delta u$ is the virtual displacement field that satisfies the displacement boundary condition and $\delta \varepsilon$ is the virtual strain field corresponding to $\delta u$.

If the entire structure is a series of finite discretized units, the total potential energy variation of the structure can be approximately expressed as the sum of the potential energy variation of each unit, and the basic equation of the finite 
TABLE 1: Model parameters.

\begin{tabular}{lcccc}
\hline Model & Model1 & Model2 & Model3 & Model4 \\
\hline Concrete strength grade & C60 & C60 & C60 \\
Stirrups in the core area & $Æ 10 @ 50$ & $Æ 10 @ 100$ & $0.40 \%$ & Æ10@150 \\
Core area volume matching rate & $0.80 \%$ & 0.75 & $0.26 \%$ & 0.75 \\
Design axial compression ratio & 0.75 & 0.75 \\
\hline
\end{tabular}

TABLe 2: Statistical table of ultimate load and displacement of each model.

\begin{tabular}{|c|c|c|c|c|}
\hline Model & Model1 & Model2 & Model3 & Model4 \\
\hline Core area volume matching rate & $0.80 \%$ & $0.40 \%$ & $0.26 \%$ & $0.20 \%$ \\
\hline Ultimate load $(\mathrm{kN})$ & 5655.68 & 5377.89 & 5257.56 & 5108.60 \\
\hline Limit displacement (mm) & 37.94 & 33.41 & 31.07 & 28.77 \\
\hline
\end{tabular}

element for the dynamic problem can be obtained. Taking a three-dimensional 8-node solid element as an example, the structural finite element discretization can be expressed as follows [22].

Within each unit, the coordinates of any point can be obtained by interpolation of the node coordinate values, namely,

$$
x_{i}(\xi, \eta, \varsigma, t)=\sum_{j=1}^{8} \phi_{j}(\xi, \eta, \varsigma) x_{i}^{j}(t) .
$$

In the formula, $\xi, \eta, \varsigma$ is the unit coordinate, as shown in Figure 3 . is

In the formula, the interpolation function (shape function)

$$
\phi_{j}(\xi, \eta, \varsigma)=\frac{1}{8}\left(1+\xi_{j} \xi\right)\left(1+\eta_{j} \eta\right)\left(1+\varsigma_{j} \varsigma\right)
$$

Among them, $\left(\xi_{j}, \eta_{j}, \varsigma_{j}\right)$ is the coordinate of the $j$ th node of the element, and the above formula can be expressed in matrix form [23]:

$$
X(\xi, \eta, \varsigma, t)=N \cdot X^{e}
$$

Among them, $X(\xi, \eta, \varsigma, t)$ is the position coordinate of any point in the unit (including three components), $X^{e}$ is the position coordinate array of each node of the unit at time $t$, and $X(\xi, \eta, \varsigma, t)=N \cdot X^{e}$ is the interpolation function matrix, which can be written in the following form:

$$
N(\xi, \eta, \varsigma)=\left[N_{1}, \cdots, N_{8}\right]
$$

In the formula, the $j$ th subblock is $N_{j}=\phi_{j} I_{3 \times 3}$.

When the whole structure is a series of discrete elements, it can be obtained from the principle of virtual displacement:

$$
\delta \prod=\sum_{e} \delta \prod_{m}=\sum_{e} \delta X^{e T}\left[\int_{v_{e}} \rho N^{T} N d V \ddot{X}^{e}+\int_{v_{e}} B^{T} \sigma d V-\int_{v_{e}} N^{T} f d V-\int_{\partial b_{2 e}} N^{T} \bar{T} d S\right]=0 .
$$

Among them, the Cauchy stress vector is

$$
\sigma=\left[\sigma_{x}, \sigma_{y}, \sigma_{z}, \sigma_{x y}, \sigma_{y z}, \sigma_{z x}\right]^{T}
$$

The strain matrix is

$$
B=L N
$$

$L$ is the differential operator matrix, and its specific elements are

$$
L^{T}=\left[\begin{array}{cccccc}
\partial_{x} & 0 & 0 & \partial_{y} & 0 & \partial_{z} \\
0 & \partial_{y} & 0 & \partial_{x} & \partial_{z} & 0 \\
0 & 0 & \partial_{z} & 0 & \partial_{y} & \partial_{x}
\end{array}\right]
$$

In LS-DYNA, since the elements of the same row in the uniform unit mass matrix $m^{e}=\int_{v_{e}} \rho N^{T} N d V$ are merged into the diagonal elements to form a concentrated mass matrix and then integrated into the overall diagonal mass matrix $M$, the above formula can be rewritten as

$$
M \ddot{X}=P(t)-F
$$

The above formula is the discretized equation of motion, where $M$ is the overall mass matrix and $F$ is formed by the collection of element stress divergence vectors, which can be obtained by the following formula:

$$
F=\sum_{e} \int_{v_{e}} B^{T} \sigma d V
$$

$p$ is the overall nodal load vector, which is formed by concentrated nodal force, surface force, physical force, etc. The formula is as follows:

$$
P=\sum_{e}\left(\int_{v_{e}} N^{T} f d V+\int_{\partial b_{2 e}} N^{T} \bar{T} d S\right) .
$$




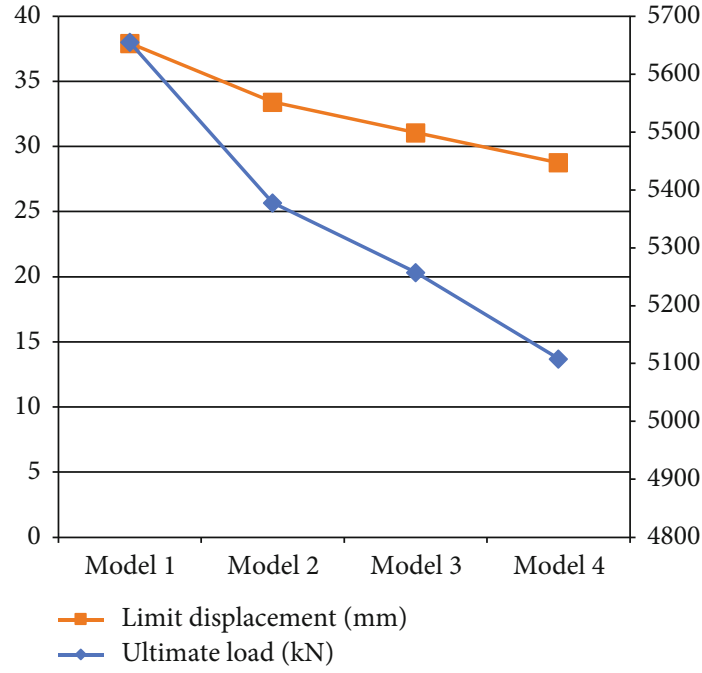

FIGURE 6: Statistical diagrams of ultimate load and displacement of each model.

The discretized structure motion equation of LS-DYNA3D considering the influence of damping is

$$
M \ddot{X}=P-F+H-C \dot{X} .
$$

The time integral adopts the principle of explicit central difference, and the format is as follows:

$$
\begin{gathered}
\ddot{X}=M^{-1}\left[P\left(t_{n}\right)-F\left(t_{n}\right)+H\left(t_{n}\right)-C \dot{X}\left(t_{n-1 / 2}\right)\right], \\
\dot{X}\left(t_{n+1 / 2}\right)=\dot{X}\left(t_{n-1 / 2}\right)+\ddot{X}\left(t_{n}\right) \frac{\left(\Delta t_{n-1}+\Delta t_{n}\right)}{2}, \\
X\left(t_{n+1 / 2}\right)=X\left(t_{n}\right)+\dot{X}\left(t_{n+1 / 2}\right) \Delta t_{n} .
\end{gathered}
$$

Among them, $t_{n-1 / 2}=\left(t_{n}+t_{n-1}\right) / 2, t_{n+1 / 2}=\left(t_{n}+t_{n-1}\right) / 2$, $\Delta t_{n-1}=\left(t_{n}-t_{n-1}\right), \Delta t_{n}=\left(t_{n+1}-t_{n}\right), \ddot{X}\left(t_{n}\right), \dot{X}\left(t_{n+1 / 2}\right)$, and $X$ $\left(t_{n+1}\right)$ are the node acceleration vector at time $t_{n}$, the node velocity vector at time $t_{n+1 / 2}$, the node position coordinate vector at time $t_{n+1}$, and so on.

Its characteristics are the following:

(1) Calculation cost is saved. For each incremental step of the nonlinear analysis, the stiffness matrix is changing, and the explicit method does not form the overall stiffness matrix. The elastic term is placed in the internal force, avoiding the inversion of the stiffness matrix. This avoids the computational cost of repeatedly updating the stiffness matrix and solving the linear equations, which is meaningful for nonlinear analysis

(2) Higher computational efficiency can be obtained. When the mass matrix of the system is a diagonal matrix, when using the above recursive formula to solve the equation of motion, it is only necessary to use the matrix multiplication to obtain the equivalent load vector at the right end, and there is no need to invert the mass matrix, so the calculation efficiency is quite high

(3) The method is conditionally stable. The stable condition is that a relatively small time step is required. If this step is exceeded, the calculation will be unstable and the displacement tends to be infinite

In order to ensure convergence, LS-DYNA3D adopts the variable step integration method. The integration step used must be less than a certain critical value; otherwise, the algorithm will be unstable. The smallest unit in the grid will determine the time step selection, namely,

$$
\Delta t=\min \left\{\Delta t_{e 1}, \cdots, \Delta t_{e N}\right\} .
$$

Among them, $\Delta t_{e i}$ is the limit time step length of the $i$ th unit and $N$ is the total number of units.

In LS-DYNA3D, the limit time step length of each type of element can be unified into the following form:

$$
\Delta t_{e}=\alpha\left(\frac{L}{c}\right)
$$

Among them, $\alpha$ is a time step factor less than 1 , which is defaulted to 0.9 by the program, $L$ is the characteristic scale of the element, and $c$ is the sound velocity of the material. The calculation formulas for the corresponding $L$ and $c$ of the solid element are

$$
\begin{gathered}
L=\frac{V_{e}}{A_{e \max }}, \\
c=\sqrt{\frac{E(1-\mu)}{\left(1-\mu^{2}\right) \rho} .}
\end{gathered}
$$

\section{Building Structure Simulation System Based on BIM and Computer Model}

Because the material properties and performance of steel bars and concrete are quite different, it is not enough to simulate reinforced concrete structures with simple linear elastic methods. Therefore, this paper uses a nonlinear analysis method for this composite material. However, the commonly used finite element analysis software cannot accurately describe complex composite building structures, such as the variable cross-section and hollow structure of the frame-core tube structure.

In the structure, the column, as an important force-bearing member, not only bears the vertical force but also bears the role of horizontal force. In a large number of earthquake disasters, the shear damage of the structure accounts for a relatively large proportion. In order to achieve the "three-level" seismic target and ensure that the overall structure does not suffer serious damage, the study of the shear capacity of the column is particularly important. Since the 21st century, the finite element analysis method has been applied more and more widely in structural calculations. It can not only simulate the development of cracks in the structure and the failure process of the 
TABLE 3: Longitudinal reinforcement ratio models of different core areas.

\begin{tabular}{|c|c|c|c|c|c|c|}
\hline Model & Model1 & Model2 & Model3 & Model4 & Model5 & Model6 \\
\hline Concrete strength grade & C60 & C60 & C60 & C60 & C60 & C60 \\
\hline Column core longitudinal rib & $28 \Phi 14$ & $28 \Phi 18$ & $28 \Phi 22$ & $28 \Phi 28$ & $28 \Phi 32$ & $28 \Phi 36$ \\
\hline Longitudinal reinforcement ratio of core area & $0.68 \%$ & $1.13 \%$ & $1.68 \%$ & $2.73 \%$ & $3.56 \%$ & $4.49 \%$ \\
\hline Stirrups in the core area & Æ10@100 & Æ10@100 & Æ10@100 & Æ10@100 & Æ10@100 & Æ10@100 \\
\hline Design axial compression ratio & 0.75 & 0.75 & 0.75 & 0.75 & 0.75 & 0.75 \\
\hline
\end{tabular}

structure as a whole but also calculate the weak parts and ultimate bearing capacity of the structure.

The load-displacement curves of reinforced concrete frame columns under monotonic loads, the shear capacity and failure mechanism of reinforced concrete frame columns under oblique horizontal loads, and the joints of high-strength concrete column-beam frame joints were analyzed using finite element software and theory, respectively. The hysteresis performance and the strength of the reinforced concrete frame short column under monotonic load are calculated and analyzed. The calculation results of the finite element software and the experimental results are compared to the two, indicating that the data obtained by the finite element software and the theory have a high reference value.

This paper takes the columns with central reinforcement as the research object and uses the VFEAP finite element software for analysis and research. Moreover, by considering influencing factors such as stirrup reinforcement ratio, longitudinal reinforcement ratio, concrete strength, and axial compression ratio, this paper establishes a series of comparative models to analyze the ultimate bearing capacity, stiffness degradation, and ductility performance changes of core columns under different influencing factors. The structural model is shown in Figure 4, and the simulation model based on BIM and computer is shown in Figure 5.

In order to specifically evaluate the role of stirrups in the core area of columns with central reinforcement, four columns with central reinforcement models with different stirrup spacings were established. In this paper, other parameters are kept unchanged, and the load-displacement curve and the stiffness degradation curve are used to study the influence of the spacing between the steel bars in the core area on the columns with central reinforcement. The model parameters are shown in Table 1.

The ultimate load and displacement of each model are shown in Table 2 and Figure 6.

The arrangement of longitudinal reinforcement in the core area of the column is the core of the columns with central reinforcement. Even if the outer concrete fails and exits work, the longitudinal reinforcement and stirrups in the core area can restrain the concrete in the core area to maintain good working performance. Therefore, the longitudinal reinforcement ratio of the core area is an important influencing factor for columns with central reinforcement. In this paper, the ratio of longitudinal reinforcement is changed by changing the diameter of the longitudinal reinforcement in the core area. A total of 6 models have been established. The diameter of the longitudinal reinforcement is $14 \mathrm{~mm}-36 \mathrm{~mm}$. The parameters are shown in Table 3.
TABLE 4: Statistical table of ultimate load and displacement of each model.

\begin{tabular}{lccc}
\hline Model & $\begin{array}{c}\text { Longitudinal } \\
\text { reinforcement ratio } \\
\text { of core area }\end{array}$ & $\begin{array}{c}\text { Ultimate } \\
\text { load }(\mathrm{kN})\end{array}$ & $\begin{array}{c}\text { Limit } \\
\text { displacement } \\
(\mathrm{mm})\end{array}$ \\
\hline Model1 & $0.68 \%$ & 5105.944 & 29.0678 \\
Model2 & $1.13 \%$ & 5247.071 & 30.8959 \\
Model3 & $1.68 \%$ & 5283.229 & 31.3201 \\
Model4 & $2.73 \%$ & 5322.831 & 32.6028 \\
Model5 & $3.56 \%$ & 5377.886 & 33.4108 \\
Model6 & $4.49 \%$ & 5547.162 & 36.2085 \\
\hline
\end{tabular}

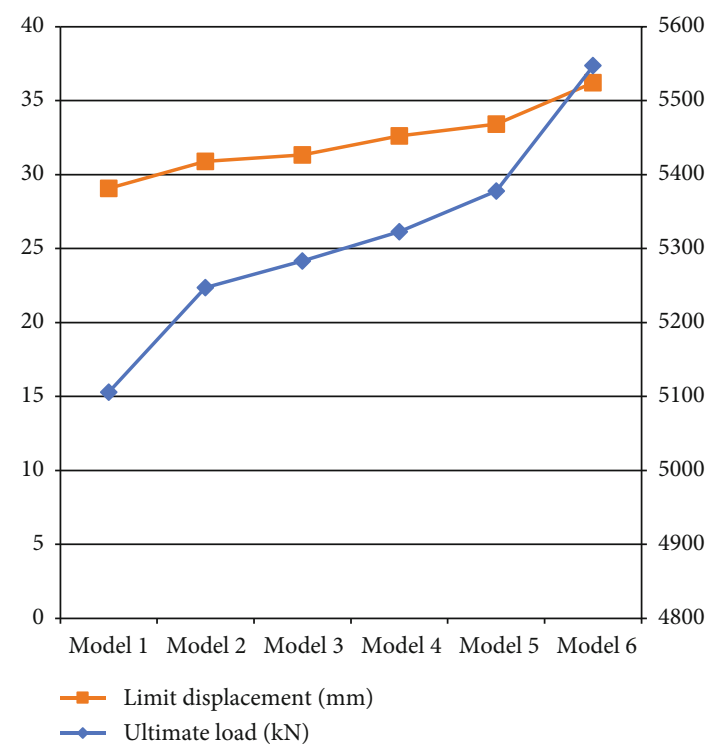

FIgURE 7: Statistical diagram of ultimate load and displacement of each model.

Among the longitudinal reinforcement ratios of $0.68 \%$ $4.46 \%$ in the core area, the ultimate load and ultimate displacement have a clear upward trend with the increase of the reinforcement ratio. The above shows that the longitudinal reinforcement in the core area plays the role of bearing the load in the middle and later stages of the component loading. With the increase of the reinforcement ratio of the longitudinal reinforcement in the core area, the lateral resistance gradually increases, and the failure of the component is delayed. 
TABLE 5: Statistical table of structural simulation effect evaluation of building structure simulation system based on BIM and computer model.

\begin{tabular}{|c|c|c|c|c|c|}
\hline Num & $\begin{array}{c}\text { Simulation } \\
\text { effect } \\
\text { evaluation }\end{array}$ & Num & $\begin{array}{l}\text { Simulation } \\
\text { effect } \\
\text { evaluation }\end{array}$ & Num & $\begin{array}{c}\text { Simulation } \\
\text { effect } \\
\text { evaluation }\end{array}$ \\
\hline 1 & 89.23 & 25 & 91.77 & 49 & 90.60 \\
\hline 2 & 93.15 & 26 & 92.41 & 50 & 88.10 \\
\hline 3 & 91.81 & 27 & 88.50 & 51 & 79.38 \\
\hline 4 & 81.07 & 28 & 79.55 & 52 & 84.02 \\
\hline 5 & 85.87 & 29 & 91.15 & 53 & 92.93 \\
\hline 6 & 88.62 & 30 & 90.15 & 54 & 92.72 \\
\hline 7 & 89.06 & 31 & 82.89 & 55 & 82.35 \\
\hline 8 & 92.88 & 32 & 87.04 & 56 & 85.23 \\
\hline 9 & 83.73 & 33 & 79.34 & 57 & 90.05 \\
\hline 10 & 80.57 & 34 & 82.85 & 58 & 84.31 \\
\hline 11 & 80.87 & 35 & 80.95 & 59 & 85.37 \\
\hline 12 & 90.91 & 36 & 87.89 & 60 & 82.08 \\
\hline 13 & 81.90 & 37 & 89.87 & 61 & 86.42 \\
\hline 14 & 92.57 & 38 & 81.83 & 62 & 87.92 \\
\hline 15 & 87.21 & 39 & 84.90 & 63 & 89.85 \\
\hline 16 & 90.98 & 40 & 93.33 & 64 & 88.14 \\
\hline 17 & 83.70 & 41 & 91.28 & 65 & 92.10 \\
\hline 18 & 84.27 & 42 & 93.51 & 66 & 92.48 \\
\hline 19 & 88.06 & 43 & 82.46 & 67 & 92.71 \\
\hline 20 & 86.41 & 44 & 84.18 & 68 & 81.00 \\
\hline 21 & 83.19 & 45 & 91.03 & 69 & 91.56 \\
\hline 22 & 79.52 & 46 & 88.18 & 70 & 83.75 \\
\hline 23 & 83.89 & 47 & 93.59 & 71 & 87.06 \\
\hline 24 & 83.24 & 48 & 87.79 & 72 & 90.70 \\
\hline
\end{tabular}

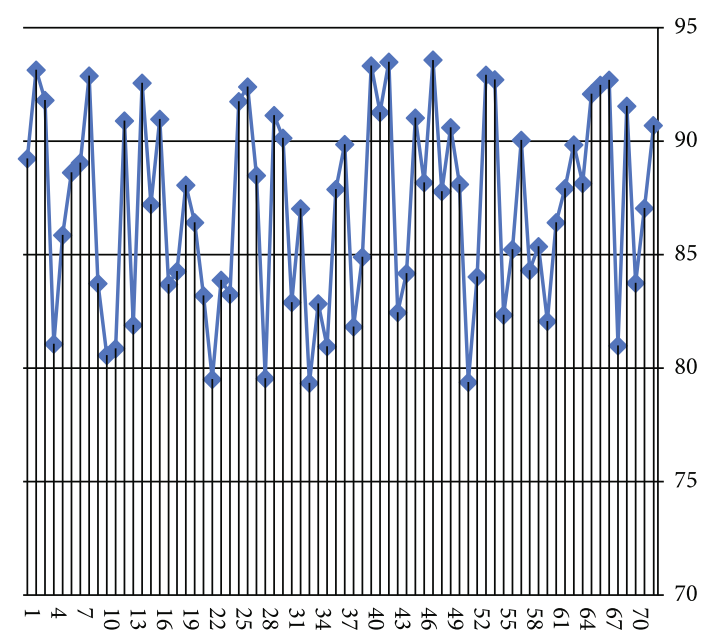

FIGURE 8: Statistical table of structural simulation effect evaluation of building structure simulation system based on BIM and computer model.
TABLE 6: Statistical table of system dynamic simulation effect evaluation.

\begin{tabular}{|c|c|c|c|c|c|}
\hline Num & $\begin{array}{c}\text { Dynamic } \\
\text { simulation } \\
\text { effect }\end{array}$ & Num & $\begin{array}{c}\text { Dynamic } \\
\text { simulation } \\
\text { effect }\end{array}$ & Num & $\begin{array}{c}\text { Dynamic } \\
\text { simulation } \\
\text { effect }\end{array}$ \\
\hline 1 & 78.1 & 25 & 81.9 & 49 & 74.5 \\
\hline 2 & 74.5 & 26 & 67.8 & 50 & 82.9 \\
\hline 3 & 74.8 & 27 & 71.5 & 51 & 85.1 \\
\hline 4 & 74.0 & 28 & 80.8 & 52 & 83.8 \\
\hline 5 & 83.7 & 29 & 81.4 & 53 & 79.2 \\
\hline 6 & 86.2 & 30 & 83.6 & 54 & 67.9 \\
\hline 7 & 67.6 & 31 & 79.6 & 55 & 78.2 \\
\hline 8 & 73.4 & 32 & 88.3 & 56 & 81.0 \\
\hline 9 & 73.2 & 33 & 89.6 & 57 & 72.2 \\
\hline 10 & 79.8 & 34 & 83.0 & 58 & 73.7 \\
\hline 11 & 83.6 & 35 & 90.5 & 59 & 82.2 \\
\hline 12 & 88.9 & 36 & 80.7 & 60 & 73.0 \\
\hline 13 & 79.3 & 37 & 78.3 & 61 & 82.0 \\
\hline 14 & 74.8 & 38 & 76.7 & 62 & 70.2 \\
\hline 15 & 75.0 & 39 & 80.6 & 63 & 70.4 \\
\hline 16 & 78.9 & 40 & 83.7 & 64 & 90.1 \\
\hline 17 & 84.3 & 41 & 87.2 & 65 & 78.7 \\
\hline 18 & 90.2 & 42 & 80.3 & 66 & 68.8 \\
\hline 19 & 80.4 & 43 & 74.3 & 67 & 88.1 \\
\hline 20 & 77.9 & 44 & 88.0 & 68 & 74.5 \\
\hline 21 & 74.8 & 45 & 72.2 & 69 & 70.8 \\
\hline 22 & 80.3 & 46 & 84.5 & 70 & 73.2 \\
\hline 23 & 76.7 & 47 & 79.5 & 71 & 74.7 \\
\hline 24 & 73.1 & 48 & 84.1 & 72 & 85.1 \\
\hline
\end{tabular}

The ultimate load and displacement of each model are shown in Table 4 and Figure 7.

The outer concrete cracked, and the stiffness suddenly dropped. When the component reaches the ultimate load, the higher the longitudinal reinforcement ratio, the slower the rate of stiffness degradation and the more complete the stiffness degradation. The longitudinal reinforcement in the core area can effectively alleviate the stiffness degradation of the component, thereby improving its lateral resistance.

Through the above analysis, it can be known that the system constructed in this paper has certain effects, which are basically consistent with the actual situation. On this basis, this article simulates multiple building structures through a computer simulation model and statistically simulates the data processing effect of the model. A total of 72 sets of data are simulated through the simulation of the building of a certain commercial center, and the results of the statistical simulation are shown in Table 5 and Figure 8.

From the above analysis results, the building structure simulation system based on BIM and computer model constructed in this paper performs well in structural simulation. Next, the effect of the dynamic simulation of the system is evaluated, and the results are shown in Table 6 and Figure 9.

From the above simulation results, the dynamic simulation effect of the system constructed in this paper is better, 


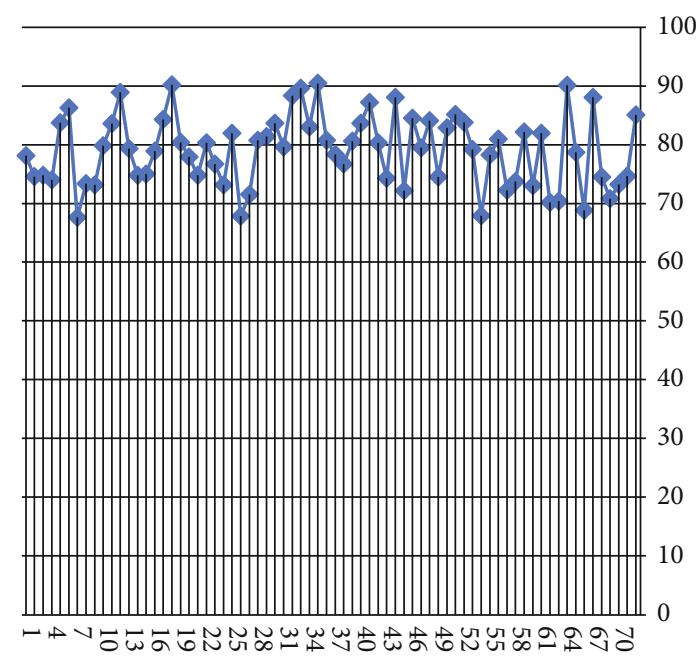

Figure 9: Statistical diagram of system dynamic simulation effect evaluation.

so the system constructed in this paper can be used for simulation analysis in subsequent building structure simulation.

\section{Conclusion}

Computer graphics simulation is a comprehensive computer technology involving multiple disciplines, and building structure simulation is a major and difficult subject in the engineering field. This paper does some research and discussion on the finite element analysis of a building structure, especially the computer graphics simulation method in building structure distribution. Because building structure simulation is a complex and huge research topic, the damage mechanism of structures under various loads is still under constant research and exploration. Therefore, this paper builds a building structure simulation system with the support of BIM and finite element technology and combines the actual building to simulate the physical structure of the building and evaluates the effect of this system. The research results show that the building structure simulation system constructed in this paper has a certain effect.

\section{Data Availability}

The data used to support the findings of this study are available from the corresponding author upon request.

\section{Conflicts of Interest}

The authors declare no competing interests.

\section{Acknowledgments}

This study is sponsored by the Key projects of natural science research in Anhui Colleges and Universities "The application research on reconstruction of historic building BIM model based on 3D scanning and UAV tilt photography" (KJ2020A1000), Key projects of natural science research in Anhui Colleges and Universities "Test and Simulation Analysis on steering device of externally prestressed box girder bridge with corrugated steel webs" (KJ2019A1134), High level professional group of provincial quality engineering in Colleges and universities (Higher Vocational Education) (2020zyq61), and Anhui teaching team project (2020jxtd186).

\section{References}

[1] X. Feng, D. Yan, and C. Wang, "On the simulation repetition and temporal discretization of stochastic occupant behaviour models in building performance simulation," Journal of Building Performance Simulation, vol. 10, no. 5-6, pp. 612-624, 2017.

[2] B. Mou, B. J. He, D. X. Zhao, and K. W. Chau, "Numerical simulation of the effects of building dimensional variation on wind pressure distribution," Engineering Applications of Computational Fluid Mechanics, vol. 11, no. 1, pp. 293-309, 2017.

[3] D. Chakraborty and H. Elzarka, "Advanced machine learning techniques for building performance simulation: a comparative analysis," Journal of Building Performance Simulation, vol. 12, no. 2, pp. 193-207, 2019.

[4] O. Guerra-Santin and S. Silvester, "Development of Dutch occupancy and heating profiles for building simulation," Building Research \& Information, vol. 45, no. 4, pp. 396-413, 2017.

[5] T. Dodd, C. Yan, and I. Ivanov, "Simulation-based methods for model building and refinement in cryoelectron microscopy," Journal of Chemical Information and Modeling, vol. 60, no. 5, pp. 2470-2483, 2020.

[6] T. Abuimara, W. O'Brien, B. Gunay, and J. S. Carrizo, "Towards occupant-centric simulation-aided building design: a case study," Building Research \& Information, vol. 47, no. 8, pp. 866-882, 2019.

[7] P. Remmen, M. Lauster, M. Mans, M. Fuchs, T. Osterhage, and D. Müller, "TEASER: an open tool for urban energy modelling of building stocks," Journal of Building Performance Simulation, vol. 11, no. 1, pp. 84-98, 2018.

[8] N. Endo, E. Shimoda, K. Goshome, T. Yamane, T. Nozu, and T. Maeda, "Simulation of design and operation of hydrogen energy utilization system for a zero emission building," International Journal of Hydrogen Energy, vol. 44, no. 14, pp. 7118-7124, 2019.

[9] I. Beausoleil-Morrison, "Learning the fundamentals of building performance simulation through an experiential teaching approach," Journal of Building Performance Simulation, vol. 12, no. 3, pp. 308-325, 2019.

[10] C. Xiong, J. Huang, and X. Lu, "Framework for city-scale building seismic resilience simulation and repair scheduling with labor constraints driven by time-history analysis," Computer-Aided Civil and Infrastructure Engineering, vol. 35, no. 4, pp. 322-341, 2020.

[11] A. D. Black, "Wor (l) d-building: simulation and metaphor at the Mars Desert Research Station," Journal of Linguistic Anthropology, vol. 28, no. 2, pp. 137-155, 2018.

[12] K. Hanson, L. Hernandez, and J. A. Banaski Jr., "Building simulation exercise capacity in Latin America to manage public health emergencies," Health Security, vol. 16, no. S1, pp. S98-S-102, 2018.

[13] E. K. Wati and N. Widiansyah, "Design of learning media: modeling \& simulation of building thermal comfort optimization system in building physics course," Jurnal Pendidikan IPA Indonesia, vol. 9, no. 2, pp. 257-266, 2020. 
[14] C. W. Lee and S. J. Cho, "The development of converting program from sealed geological model to Gmsh, COMSOL for building simulation grid," Journal of the Korean Earth Science Society, vol. 38, no. 1, pp. 80-90, 2017.

[15] C. Miller, D. Thomas, J. Kämpf, and A. Schlueter, "Urban and building multiscale co-simulation: case study implementations on two university campuses," Journal of Building Performance Simulation, vol. 11, no. 3, pp. 309-321, 2018.

[16] X. Xie and Z. Gou, "Building performance simulation as an early intervention or late verification in architectural design: same performance outcome but different design solutions," Journal of Green Building, vol. 12, no. 1, pp. 45-61, 2017.

[17] A. I. Adilkhodjayev, I. M. Mahamataliev, and S. S. Shaumarov, "Theoretical aspects of structural and simulation modeling of the macrostructure of composite building materials," Journal of Tashkent Institute of Railway Engineers, vol. 14, no. 2, pp. 3-14, 2019.

[18] S. Imam, D. A. Coley, and I. Walker, "The building performance gap: are modellers literate?," Building Services Engineering Research and Technology, vol. 38, no. 3, pp. 351-375, 2017.

[19] J. S. Pei, B. Carboni, and W. Lacarbonara, "Mem-models as building blocks for simulation and identification of hysteretic systems," Nonlinear Dynamics, vol. 100, no. 2, pp. 973-998, 2020.

[20] A. Brunelli, F. de Silva, A. Piro et al., "Numerical simulation of the seismic response and soil-structure interaction for a monitored masonry school building damaged by the 2016 Central Italy earthquake," Bulletin of Earthquake Engineering, vol. 19, no. 2, pp. 1181-1211, 2021.

[21] P. Andrio, A. Hospital, J. Conejero et al., "BioExcel Building Blocks, a software library for interoperable biomolecular simulation workflows," Scientific data, vol. 6, no. 1, pp. 1-8, 2019.

[22] G. Petrou, A. Mavrogianni, P. Symonds et al., "Can the choice of building performance simulation tool significantly alter the level of predicted indoor overheating risk in London flats?," Building Services Engineering Research and Technology, vol. 40, no. 1, pp. 30-46, 2019.

[23] S. Gibeaux, C. Thomachot-Schneider, S. Eyssautier-Chuine, B. Marin, and P. Vazquez, "Simulation of acid weathering on natural and artificial building stones according to the current atmospheric SO 2/NO x rate," Environmental Earth Sciences, vol. 77, no. 9, pp. 1-19, 2018. 